\title{
Aanpassing afstammings- en gezagsrecht gewenst voor ongehuwd samenwonende ouders
}

W.M. Schrama*

De Nederlandse samenleving is in de afgelopen vier decennia compleet veranderd, waar het gaat om het relatielandschap. In de jaren zeventig werd er volop getrouwd en werden bijna alle kinderen binnen het huwelijk geboren; in 2015 werden zelfs meer eerstgeboren kinderen buiten dan binnen het huwelijk geboren. Het afstammings- en gezagsrecht, de twee gebieden die in dit opzicht juridisch van belang zijn, zijn van oorsprong uitsluitend op het huwelijk gericht. Het huwelijk was lange tijd het enige model voor relaties. De vlucht die het ongehuwd samenwonen heeft genomen, is een ontwikkeling die zich in veel westerse landen voordoet en die de wetgever voor de kwestie plaatst welke gevolgen deze relatie heeft voor de rechtsverhouding tussen ouders en kinderen. De vraag is in hoeverre beide rechtsgebieden zich voldoende hebben aangepast aan de maatschappelijke veranderingen. Dit onderwerp heeft in Nederland recent politieke aandacht gekregen. In de eerste plaats heeft de Staatscommissie Herijking Ouderschap de opdracht gekregen om na te denken over afstamming en gezag in het licht van de maatschappelijke ontwikkelingen; het advies zal eind 2016 verschijnen. ${ }^{1}$ In de tweede plaats kondigde D66 ${ }^{2}$ in maart 2016 aan dat zij een wetsvoorstel zal indienen gericht op de verbetering van de rechtspositie van ongehuwde vaders, met name door een aanpassing van het gezagsrecht. Dit laatste is het eerste teken in lange tijd dat de positie van deze grote groep kinderen en ouders ook op de agenda van de politieke partijen staat.

In deze bijdrage staat de vraag centraal hoe de doelen van het familierecht zo goed mogelijk kunnen worden gerealiseerd. Daartoe worden

\footnotetext{
* Prof. mr. Wendy Schrama is als hoogleraar familierecht en rechtsvergelijking verbonden aan het Utrecht Centre for European Research into Family Law van het Molengraaff Instituut voor Privaatrecht van de Universiteit Utrecht.

1 Kamerstukken I/ 2013/14, 33863, 2.

2 Zie de website van D66: https://d66.nl/gelijke-rechten-ongetrouwde-vaders.
} 
hierna enkele cijfers gegeven aan de hand waarvan de maatschappelijke context wordt geschetst. Vervolgens wordt ingegaan op het Nederlandse afstammingsrecht en het gezagsrecht, terwijl daarna aandacht wordt besteed aan de doelen die met deze wetgeving op beide terreinen worden nagestreefd. Of, en welke, problemen zich voordoen in de regeling van het afstammings- en gezagsrecht komt ook aan bod, evenals de vraag of het familierecht met een aanpassing de onderscheiden doelen beter kan realiseren. Ten slotte wordt ingegaan op een mogelijke oplossing.

\section{Maatschappelijke context}

De maatschappelijke veranderingen zijn hard gegaan waar het gaat om de geboorte van kinderen gerelateerd aan de relatievorm van hun ouders. In de jaren zeventig bedroeg het percentage buitenhuwelijks geboren kinderen ongeveer $2 \%$ (1975, CBS, StatLine-database). Dat percentage is tegenwoordig opgelopen tot $44 \%$ van alle baby's, en zelfs tot $52 \%$ van alle eerstgeboren kinderen (2015, CBS, StatLine-database). De maatschappelijke trend waarbij kinderen steeds minder vaak tijdens het huwelijk van hun ouders geboren worden, zet zich nog altijd voort, maar de laatste jaren stijgt het percentage niet meer zo snel (CBS 2016).

\section{Juridische context}

Bij de relatie tussen ouders en kinderen gaat het binnen het familierecht om twee vraagstukken: afstamming en gezag. Dat zijn twee rechtsbetrekkingen tussen volwassenen en kinderen, waarvoor aparte regels gelden: het afstammingsrecht, geregeld in titel 11 van Boek 1 van het Burgerlijk Wetboek (BW), en gezag, neergelegd in titel 14 van Boek 1 BW. Beide rechtsbetrekkingen hebben hun eigen kenmerken en regelen een ander aspect. Afstamming regelt wie de juridische ouders van een kind zijn. Eenmaal vader of moeder zijn daaraan veel rechtsgevolgen verbonden, bijvoorbeeld in het naamrecht, erfrecht en nationaliteitsrecht. Gezagsrecht regelt wie de opvoedverantwoordelijkheid hebben voor een minderjarig kind. Een aantal decennia geleden lagen afstamming en gezag meestal in dezelfde handen, namelijk 
in die van getrouwde ouders. Het recht dat de relatie tussen ouders en kinderen regelt, is traditioneel aldus sterk op het huwelijksmodel gebaseerd. Onwettige kinderen, bastaarden of kinderen geboren uit 'verboden' relaties zijn lange tijd door recht en maatschappij sterk achtergesteld (Asser/De Boer 1*2010/689). Het afstammingsrecht heeft lange tijd een belangrijke rol vervuld bij het in stand houden van morele opvattingen door een scherp onderscheid te maken tussen kinderen geboren binnen het huwelijk en buiten het huwelijk en kinderen geboren uit overspel en incest. Het afstammingsrecht bepaalde bijvoorbeeld dat voor deze laatste groep kinderen geen afstammingsband met hun vader en moeder ontstond; zij hadden dus een rechteloze positie. Ook de positie van kinderen buiten het huwelijk geboren (maar zonder incest of overspel) was aanmerkelijk slechter dan die van huwelijkse kinderen (Asser/De Boer $1^{*} 2010 / 690$ ). Die tijd is voorbij. Er zijn sindsdien verschillende stappen gezet ter verbetering van de rechtspositie van kinderen die buiten het huwelijk zijn geboren. In 1982 vonden belangrijke verbeteringen plaats en in 1998 bijvoorbeeld werden de termen onwettig kind en natuurlijk kind uit het BW geschrapt. Maar dat betekent nog niet dat het ouder-kindrecht zich inmiddels optimaal heeft aangepast aan het nieuwe maatschappelijke gegeven dat een meerderheid van de eerstgeboren kinderen buiten het huwelijk wordt geboren.

De situatie is juridisch nu als volgt. Als een kind wordt geboren, heeft het altijd een moeder, namelijk de vrouw uit wie het wordt geboren (art. 1:198 lid 1 onder a BW). Hierna zal het dan ook voornamelijk om de positie van vaders gaan; voor moeders bestaan al goede wettelijke regelingen. Of het kind ook meteen bij zijn geboorte een juridische vader heeft, hangt ervan af. Wordt het geboren binnen een huwelijk of geregistreerd partnerschap, dan is de partner van de moeder de vader van het kind, zonder dat daarvoor iets hoeft te gebeuren (art. 1:199 onder a BW). Huwelijk en geregistreerd partnerschap hebben in dit opzicht dus precies dezelfde gevolgen. In dit scenario hebben de moeder en de vader ook automatisch gezamenlijk gezag over het kind (art. 1:251 lid $1 \mathrm{BW}$ ). Met andere woorden: het is in één keer op beide punten en van rechtswege geregeld. Wordt een kind geboren bij twee ongehuwde (samenlevende) ouders, dan heeft het kind wel een moeder, maar niet automatisch een vader. ${ }^{3}$ Niet van belang hierbij is of de

3 Voor meemoeders bestaan dezelfde mogelijkheden; dit wordt hierna verder buiten beschouwing gelaten. 
ouders een samenlevingscontract hebben; met of zonder contract geldt iedereen als niet-gehuwd en niet-geregistreerd paar. Het recht biedt voor deze groep dan wel geen automatisch vaderschap, maar wel een eenvoudige manier voor de man om vader te worden: erkenning van het kind (art. 1:204 BW). Dat vereist actie van de ouders, maar is laagdrempelig en vindt doorgaans plaats bij de ambtenaar van de burgerlijke stand. Dat kan voorafgaand aan de geboorte van het kind, bij de geboorteaangifte of na de geboorteaangifte. Daarbij moet een aantal documenten, zoals een identiteitsbewijs van de vader, worden overgelegd. De ambtenaar van de burgerlijke stand gaat na of aan de voorwaarden voor erkenning is voldaan. Een voorwaarde is dat de moeder toestemming geeft voor de erkenning van een kind onder de 16 jaar (art. 1:204 lid 1 onder c BW). Oorspronkelijk werd beoogd de vrouw zo te beschermen tegen erkenning van haar kind door een man uit een lagere maatschappelijke klasse, die zich aldus aan haar zou kunnen opdringen (Asser/De Boer $1^{*}$ 2010/726). Ook nu is het impliciete idee dat de vrouw zo beschermd wordt tegen ongewenste inmenging in haar privé- en familieleven, maar er wordt nu, onder invloed van artikel 8 van het Europees Verdrag voor de Rechten van de Mens (EVRM), dat bescherming biedt aan het familieleven, meer gewicht toegekend aan de positie van de vader en het belang van het kind een vader te hebben.

Als de man het kind erkend heeft, is hij weliswaar de vader, maar daarmee heeft hij nog niet het gezag. Hij heeft dus geen opvoedrecht en -plicht. Daarvoor moeten de ouders samen gezamenlijk gezag laten aantekenen. Dat loopt niet via de ambtenaar van de burgerlijke stand, maar via de griffie van de rechtbank. Er dient een aantal documenten te worden ingeleverd. Er vindt geen inhoudelijke beoordeling plaats (art. 1:252 BW). Tegenwoordig kan het verzoek ook digitaal worden gedaan. ${ }^{4}$ Voor het verkrijgen van gezag van de vader is niet expliciet de toestemming van de moeder vereist, maar impliciet wel, nu een verzoek om op deze manier gezamenlijk gezag te krijgen alleen door de beide ouders samen gedaan kan worden. Hebben ouders eenmaal gezamenlijk gezag, dan blijft dat doorlopen, ook als de ouders uit elkaar gaan. Dat geldt of ze nu getrouwd waren, een geregistreerd partnerschap hadden, of geen van beide (art. 1:251 lid 2 BW). 


\section{Doelen van afstammings- en gezagsrecht}

Om te beoordelen of het familierecht op deze terreinen verdere aanpassing behoeft om recht te doen aan de sterk gewijzigde maatschappelijke omstandigheden, is van belang na te gaan welke doelen met beide groepen rechtsregels worden nagestreefd. Deze aandacht voor doelen roept wellicht het beeld op van een technische benadering, terwijl het juist gaat om een onderwerp waarover het maatschappelijk debat scherp gevoerd kan worden, waar verschil in politieke opvattingen zich scherp kan aftekenen en waarin gender relevant is. Doet zo'n benadering hier wel recht aan? Een invalshoek die vertrekt vanuit de doelen van het afstammings- en gezagsrecht is echter niet zozeer technisch, als wel context gericht. Welke doelen worden nagestreefd, is namelijk een vraag die niet los kan worden gezien van de maatschappelijke context, de doelen worden juist ingekleurd door de huidige ontwikkelingen, met oog voor politieke en sociale druk en in het licht van maatschappelijk debat. Er is met andere woorden een duidelijke samenhang tussen maatschappelijke ontwikkelingen en de doelen van het familierecht; denk in dit verband bijvoorbeeld aan het doel van het afstammingsrecht de (seksuele) moraal te handhaven, dat in de vorige eeuw een belangrijke rol speelde.

In de huidige maatschappelijke context zijn de volgende doelen te onderscheiden. In de eerste plaats worden in het afstammings- en gezagsrecht verantwoordelijkheden geregeld: duidelijk is welke volwassenen de verantwoordelijkheid dragen voor afhankelijke kinderen. Door het wettelijk regelen en duidelijkheid scheppen over wie wel en wie niet verantwoordelijk zijn voor kinderen, zijn deze rechtsgebieden aldus niet alleen in de sleutel van de rechtszekerheid te plaatsen, maar ook in de sleutel van het verantwoordelijkheidsbeginsel (vgl. Vlaardingerbroek 2014, p. 7). Het beschermen van kinderen - in het belang van het kind - is hierbij essentieel. Het beschermingsbeginsel speelt aldus in de tweede plaats een grote rol, omdat kinderen bij hun geboorte zelf geen verantwoordelijkheid kunnen dragen. Dit draagt in de derde plaats bij aan het doel van dit rechtsterrein om conflicten tussen de ouders te voorkomen.

Het beschermingsbeginsel en verantwoordelijkheidsbeginsel worden in het afstammings- en gezagsrecht verder ingekleurd aan de hand van de maatschappelijke context. Impliciet volgt hieruit dat de regelingen erop gericht zijn dat kinderen zo veel mogelijk bescherming krijgen en 
dat rechtszekerheid over de rechtspositie bestaat, zowel voor kinderen als voor ouders. De wederom impliciete veronderstelling was onder het oude recht (voor 1998) dat optimale bescherming werd geboden als het kind werd geboren binnen de sociaal aanvaardbare relatievorm, het huwelijk. Daar zat toen (en ook nu nog) veel logica in, omdat de echtgenoten doorgaans zowel de biologische/genetische ouders van het kind zijn als de mensen die in de regel ook voor het kind gaan zorgen. Het model was er dus op gericht om biologisch, sociaal en juridisch ouderschap zo veel mogelijk te laten samenvallen. Daarmee werd de rechtspositie van ouders en kinderen het beste gediend. Dit model werkt nu niet meer zoals het bedoeld is, omdat ouders niet meer overwegend trouwen voor de geboorte van hun kind, maar het onderliggende idee is ook nu nog een doel van het afstammings- en gezagsrecht, namelijk een wettelijke regeling die doorgaans tot de beste bescherming voor kinderen en ouders leidt. Gelet op het feit dat moeders naar huidig recht altijd van rechtswege juridisch moeder worden en gezag krijgen, gaat het hierna vooral over kinderen en vaders.

\section{Problemen ter zake van het afstammingsrecht}

Een belangrijke stap bij de beantwoording van de vraag of aanpassing van wetgeving nodig is, is of er problemen zijn met het functioneren van de huidige wetgeving doordat de hierboven genoemde doelen niet voldoende worden gerealiseerd (zie hierover ook Schrama 2015, 2016a, 2016b). Voor de vraag of het afstammingsrecht zijn doelen voldoende realiseert, is empirisch inzicht over het aantal erkenningen van belang. Zouden namelijk alle vaders die ongehuwd samenwonen met de moeder van het kind hun kind voor of bij de geboorte erkennen, dan hebben deze kinderen en vaders een duidelijke rechtspositie die bescherming biedt.

Is dat ook zo in de praktijk? Uit cijfers van het Centraal Bureau voor de Statistiek (CBS) blijkt dat van de 75.000 kinderen die in 2012 buiten het huwelijk geboren werden (van de in totaal 176.000 kinderen) naar schatting $90 \%$ in het eerste jaar na hun geboorte erkend is en later nog eens 3\%. Zo'n 5.200 kinderen (7\%) zijn niet erkend. Onlangs zijn cijfers gepubliceerd over kinderen geboren in 2015. In dat jaar zijn ook 75.000 baby's buiten het huwelijk geboren. De meeste vaders van deze 
kinderen (80\%) hebben het juridische vaderschap al tijdens de zwangerschap of bij de geboorte geregeld door erkenning. De andere vaders deden dit op een later tijdstip: 7\% erkende het kind binnen een week na de geboorte, $3 \%$ deed dat later in dat jaar. Een jaar na de geboorte heeft aldus $10 \%$ van de kinderen nog geen vader. De verwachting is dat een deel van deze $10 \%$ later alsnog een vader krijgt door erkenning. Deze verwachting is gebaseerd op het gegeven dat van de kinderen die in 2010 buiten het huwelijk geboren werden en van wie in dat jaar de vader nog niet bekend was (circa 10\% van het totale aantal buiten het huwelijk geboren kinderen), ongeveer $2 \%$ binnen vijf jaar alsnog werd erkend (CBS 2016).

Deze cijfers wijzen erop dat er voor de overgrote meerderheid van de gevallen geen problemen zijn met het afstammingsrecht: de kinderen hebben twee ouders, het is bij de geboorte (of in het jaar van de geboorte) duidelijk wie dit zijn en het kind wordt aldus in rechte beschermd, omdat het een moeder en een vader heeft. Aan de andere kant geldt voor beide geboortejaren dat $10 \%$ van de vaders het kind niet binnen een jaar erkend heeft. Een deel daarvan erkent het kind later (grof geschat $2 \%$ ); een deel van deze $2 \%$ zal vermoedelijk de gang naar de rechter maken om toestemming voor de erkenning te krijgen (nadat de moeder toestemming heeft geweigerd). Dat zou betekenen dat zo'n 7\% van alle buiten het huwelijk geboren kinderen na een aantal jaren geen juridische vader heeft (5.200 kinderen geboren in 2012) en dat $2 \%$ van alle buiten het huwelijk geboren kinderen (1.500 kinderen geboren in 2012) een vader na één jaar of langer na de geboorte krijgt. Uit de rechtspraak kunnen we afleiden dat in een deel van deze gevallen tussen de ouders een conflict ontstaat over de afstamming (Schrama 2015). Helaas is niet vast te stellen in welk deel van de gevallen dat zo is, en ook niet of de ouders hebben samengewoond. Het gaat hierbij vaak om conflicten rondom een scheiding van een samenlevend stel. Zolang de relatie van de ouders goed is, is die rechtspositie van de ouders ten opzichte van het kind in feite niet relevant voor de dagelijkse gang van zaken. Voor de moeder zijn er ook na scheiding geen problemen, omdat ze automatisch moeder is. Het probleem doet zich voor bij de mannen, die bij de scheiding nog geen juridisch vader zijn, omdat toestemming van de moeder vereist is voor de erkenning. Weigert de moeder toestemming te geven, dan moet de man naar de rechter stappen, die in standaardgevallen de toestemming alsnog geeft (zie uitgebreid over de moeilijkheden en uitkomsten van deze proce- 
dures: Schrama 2015). Dit zet de verhoudingen tussen de ouders onnodig op scherp, terwijl het weigeren van toestemming meestal niet het door de moeder gewenste resultaat oplevert.

\section{Problemen gezagsrecht}

Het tweede onderwerp bij de ouder-kindrelatie is het functioneren van het gezagsrecht. Gezag gaat niet over de vraag wie de juridische ouder is, maar wie opvoedverantwoordelijkheid voor het kind (mogen en moeten) hebben. De (ongehuwde) moeder heeft automatisch gezag over het kind. Als de ongehuwde vader gezag wil krijgen, moet hij het kind eerst erkend hebben. Opmerkelijk is dat empirische gegevens schaars zijn. Over de verkrijging van gezamenlijk gezag via de registratie voor ongehuwde ouders houdt het CBS geen cijfers bij. De enige houvast die er in dit opzicht is, is dat uit de gepubliceerde rechtspraak ${ }^{5}$ blijkt dat er met enige regelmaat conflicten tussen ouders zijn bij scheiding over de vraag of de vader gezag kan krijgen samen met de moeder. Als alleen de moeder het gezag heeft over het kind, omdat de ouders geen gezamenlijk gezag hebben laten aantekenen, kan de vader namelijk naar de rechter gaan en alsnog om gezamenlijk gezag vragen of, minder gebruikelijk, om eenhoofdig gezag, dus gezag voor hem in plaats van gezag door de moeder (art. 1:253c BW). Het kan gaan om vaders die het kind tijdens de relatie erkend hebben, maar daarna het gezag niet geregeld hebben, en om vaders die ook de erkenning nog niet hebben verricht op het moment dat de relatie met de moeder stukloopt. Deze laatste groep vaders moet eerst toestemming voor erkenning krijgen en kan dan een verzoek tot gezamenlijk gezag doen. Er zijn geen (publiek toegankelijke) cijfers beschikbaar over het aantal rechtszaken dat jaarlijks gevoerd wordt over de verkrijging van gezag door de ongehuwde vader. Een eerste blik op de rechtspraak laat zien dat hierover in de eerste helft van 2016 circa twintig zaken gepubliceerd zijn op rechtspraak.nl. Gelet op het feit dat slechts een klein deel van de zaken van rechtbanken gepubliceerd wordt in deze databank, ligt het totale aantal rechtszaken veel hoger. ${ }^{6}$ Van

5 Zie www.rechtspraak.nl.

6 In de databank wordt slechts een deel van de uitspraken gepubliceerd. Zie ook Van Opijnen (2014, p. 229-230), waaruit blijkt dat in 2009 naar schatting zo'n 2,5\% van de familierechtzaken gepubliceerd werd op rechtspraak.nl. 
belang is ten slotte dat bij de rechtszaken die worden voorgelegd aan de rechter, hij in beginsel het gezamenlijk gezag dient toe te wijzen, tenzij aan een van de twee wettelijke uitzonderingsgronden is voldaan (art. 1:253c BW). De hoofdregel is dus dat ouders gezamenlijk gezag uitoefenen, ook als hun relatie voorbij is (Wortmann 2016). Er lijkt dus wel sprake van een probleem, omdat er deels onnodige conflicten aan de rechter worden voorgelegd, die het begin markeren van de jaren waarin de ouders nog wel ouders zijn, maar geen partner meer. Dat is geen fraai begin. Over de omvang van dit probleem is weinig te zeggen; cijfers hierover zijn waarschijnlijk wel te traceren via het registratiesysteem van de rechterlijke macht, maar moeten daarvoor eerst bewerkt en nader geanalyseerd worden. Het zou een goede zaak zijn als dat zou gebeuren, zodat er meer inzicht komt.

\section{Gelijkheid als probleem}

Een potentieel juridisch probleem bij zowel het afstammings- als het gezagsrecht is dat de rechtspositie van een ongehuwde moeder en ongehuwde vader niet gelijk zijn. Dat is met betrekking tot het gezagsrecht in ieder geval de stelling van D66 en het is een belangrijke drijfveer voor het plan tot aanpassing van de wetgeving. Hiermee zijn we op een terrein aangekomen waar veel ruimte is voor debat. De gevoelige discussie over de betekenis van moeders en vaders voor kinderen, die eigenlijk nog niet gevoerd is, is een lastige. Biologisch gezien is er een evident verschil tussen mannen en vrouwen, maar de discussie of dat verschillen zou rechtvaardigen, en zo ja, welke, is niet gevoerd. De rollen van moeders en vaders zijn op groepsniveau ook niet gelijk, zeker niet in Nederland (zie bijv. SCP/CBS 2014a, 2014b), waar betaalde arbeid en zorg scheef verdeeld zijn, maar of, en zo ja, welke consequenties dat moet hebben voor het afstammings- en gezagsrecht, is geen uitgemaakte zaak. De tendens lijkt te zijn dat er geen verschillen zouden moeten zijn en dat empirisch bestaande verschillen tussen vaders en moeders geen rol spelen. Dit blijkt sterk uit de Wet voortgezet ouderschap en zorgvoldige scheiding, die in 2009 is ingevoerd en waarbij kinderen en ouders recht op een gelijkwaardige verzorging en opvoeding hebben na scheiding, los van de feitelijke verschillen op groepsniveau tussen moeders en vaders. 
Het zou goed zijn om een maatschappelijk en juridisch debat te voeren over de (impliciete) ideeën over moeders en vaders en de rol van het gelijkheidsbeginsel. Los van de vraag of het gelijkheidsbeginsel zou moeten leiden tot aanpassing van het afstammings- en gezagsrecht, is er wel een andere reden om dat te overwegen, die hierna uiteengezet wordt.

\section{Beter realiseren doelen}

De vraag of het afstammings- en gezagsrecht functioneren, lijkt aldus met een voorzichtig ja te moeten worden beantwoord; voorzichtig, omdat er te weinig empirische gegevens zijn om daadwerkelijk een goed beeld te krijgen. Vervolgens kan de vraag worden gesteld of beide rechtsgebieden nog beter zouden kunnen voldoen aan de doelen waarvoor ze in het leven geroepen zijn. Daarop lijkt het antwoord, evenzeer voorzichtig, ja te zijn. Als de regel zou zijn dat alle vaders die ongehuwd samenwonen met de moeder automatisch juridisch vader worden en automatisch gezamenlijk gezag krijgen, heeft dit namelijk een aantal voordelen en weinig nadelen. In de eerste plaats is het nog laagdrempeliger dan nu, omdat de ouders helemaal niets hoeven te doen. Gemak dient de mens en het is niet nodig om hindernissen op te werpen, als daar geen goede reden voor is. Een tweede voordeel is dat een dergelijke regeling het afstammings- en gezagsrecht laat aansluiten bij een veelvoorkomende situatie. Daarmee is de rechtspositie van de betrokkenen, waaronder met name die van het kind, helder en ontstaat bij scheiding geen conflict over de vraag of de vader het kind mag erkennen of gezag mag krijgen. Dat is aldus het derde voordeel: een lager conflictpotentieel doordat de mogelijkheid die het huidige recht nu biedt aan de moeder om niet mee te werken, betekent dat er op voorhand al conflictmogelijkheden zijn. Of dat in strijd met het gelijkheidsbeginsel is, kan in het midden blijven. Duidelijk is wel dat de wetgever, die het wettelijk stelsel zo inricht dat kinderen bij voorkeur twee biologische en sociale ouders hebben, deze lijn in de huidige maatschappelijke context verder kan en mag doortrekken. Een scheve rechtspositie als die van moeders en vaders die ongehuwd samenwonen, lijkt me niet proportioneel; dat raakt aan het gelijkheidsbeginsel. Overigens betekent een aanpassing van het recht niet dat er geen conflicten meer voor de rechter worden uitgevochten; als mensen willen 
vechten, doen ze dat toch wel. Dat neemt niet weg dat de wetgever wel kan proberen om het aantal juridische aspecten waarover ruziegemaakt kan worden, te beperken.

Ook is een belangrijk punt dat de wetgever stelling neemt: als je als samenwonende volwassenen samen een kind op de wereld zet, zit je aan elkaar vast als ouders, ook als je als partners niet meer bij elkaar bent, dat geldt voor moeders (die naar huidig recht toestemming kunnen weigeren) en voor vaders (die niet automatisch vader worden). Op groepsniveau mogen er dan verschillen zijn tussen moeders en vaders, dat neemt niet weg dat de uitgangspositie in beginsel is dat beide ouders een belangrijke rol vervullen in het leven van het kind. De grondslag daarvoor is de procreatieve verantwoordelijkheid van de ouders. ${ }^{7}$ Als je handelen ertoe leidt dat er een kind geboren wordt, ben je beiden verantwoordelijk voor dat kind.

Met de aanpassing van het afstammingsrecht in 1998 is de band tussen ouder en kind die via biologie bestaat, versterkt. Gedeeltelijk is dat uitgangspunt verlaten waar het gaat om ouders van hetzelfde geslacht (die niet beiden de biologische ouder van het kind kunnen zijn), maar als uitgangspunt staat het belang van biologische afstamming niet ter discussie. Daarin past de gedachte om ook vaders die niet in een formele relatie met de moeder verbonden zijn, van rechtswege tot vader met gezag te maken. De veronderstelling is namelijk gerechtvaardigd dat de man die ongehuwd met de moeder van het kind samenwoont, de biologische vader van het kind is. Tegelijkertijd wordt daarmee doorgaans het belang van het kind gediend. Wat in het belang van het kind is in het afstammings- en gezagsrecht, is niet duidelijk verwoord in wetgeving. Impliciet is dat belang echter wel helder. Ons huidige familierecht is zo ingericht dat het kind zo veel mogelijk twee juridische ouders heeft. Daarbij wordt ernaar gestreefd om biologisch, sociaal en juridisch ouderschap zo veel mogelijk te laten samenvallen. Daaraan ligt het idee ten grondslag dat het kind de meeste stabiliteit en continuïteit heeft. Ook in het belang van het kind en de ouders is dat er zo min mogelijk ruimte voor conflict is. Ouders die bij een scheiding eerst conflicten gaan uitvechten over afstamming en/of gezag, beginnen al op slechte voet aan hun gezamenlijke ouderschap na de relatie. 
Het voorgaande houdt in dat een dergelijk streven om zo veel mogelijk kinderen twee ouders te geven, beperkt is tot de situatie waarin vaders ongehuwd samenwonen met de moeder. Voor vaders die niet samenwonen, is het niet mogelijk om een criterium te vinden - waarbij de wet zou kunnen aanknopen - op grond waarvan de wetgever mag verwachten dat juist deze mannen doorgaans de biologische en sociale vader zullen zijn. Om die reden wordt hierna alleen ingegaan op vaders die ongehuwd samenwonen met de moeder van het kind.

\section{Concreet voorstel}

Als de wetgever zou besluiten om deze stappen te zetten, dan is de volgende vraag of dit technisch haalbaar en uitvoerbaar is. Gelet op het feit dat ongehuwd samenwonen een ongeregistreerde relatievorm is, waarbij op geen enkel moment de tussenkomst van de staat vereist (of zelfs mogelijk) is, is de vraag hoe een wettelijke regeling binnen het familierecht het ongehuwd samenwonen zo zou kunnen afbakenen, dat de passende groep ouders wordt gedefinieerd. Bedacht moet hierbij worden dat het om zeer vergaande rechtsgevolgen gaat, waarbij de rechtszekerheid een bijzonder belangrijke rol speelt. Dat geldt nog meer voor het afstammingsrecht dan voor het gezagsrecht, omdat het afstammingsrecht hele families in een lange lijn plaatst, terwijl gezag ziet op een tijdelijke maatregel tot het kind meerderjarig is. Met andere woorden: er moet voldoende rechtszekerheid zijn welke vaders niet en welke wel van rechtswege vader zijn geworden en samen met de moeder automatisch gezamenlijk gezag hebben verkregen bij de geboorte van het kind.

Een oplossing zou kunnen zijn om voor een dubbele aanknoping te kiezen (Schrama 2016b). Daarbij zouden de automatische rechtsgevolgen alleen gelden als de man die geboorteaangifte van het kind doet op hetzelfde adres in de Basisregistratie Personen (BRP) ingeschreven staat als de moeder. Bij de geboorteaangifte worden de gegevens geregistreerd van de man die aangifte van de geboorte doet. De ambtenaar gaat na of deze man op hetzelfde adres als de moeder is ingeschreven in de BRP. Als dat zo is, wordt deze man van rechtswege vader van het kind, zonder dat daaraan een erkenning te pas komt. Ook heeft hij vanaf de geboorte gezamenlijk het gezag met de moeder, zonder dat daarvoor extra stappen nodig zijn. 
Er wordt een uitzondering gemaakt voor de situatie dat sprake is van te nauwe verwantschap tussen de man en de moeder (zie art. 1:204 lid 1 onder a BW); in dat geval wordt de man niet van rechtswege de vader. Deze uitzondering zal in de praktijk geen problemen opleveren. De voorgestelde regel geldt (en is alleen nodig) als het kind niet al prenataal erkend is. Toestemming van de moeder is in deze gevallen niet vereist. De one-night stand-vader valt niet onder deze regel, omdat hij niet als samenwonend met de moeder is geregistreerd en wellicht ook niet degene is die de geboorteaangifte zal doen.

Deze oplossing heeft vermoedelijk haar eigen nadelen; zo zal het niet altijd de samenwonende vader zijn die de geboorteaangifte doet; de aangifte kan ook door een ander gedaan worden. De partner van de moeder zou in dat geval niet automatisch de bijbehorende rechten en plichten krijgen (en zou het kind moeten erkennen), maar de ouders zouden daar misschien ten onrechte wel van uitgaan en dus geen stappen zetten om het kind te erkennen. Degene die in dat geval wel de aangifte doet, wordt geen vader, omdat hij niet op hetzelfde adres geregistreerd is.

In dit verband is te overwegen om informatie over de status van kinderen en wijzigingen daarin makkelijk toegankelijk voor burgers te maken via een beveiligde internetomgeving; een idee dat vanzelfsprekend niet op stel en sprong uitgevoerd is, al laat bijvoorbeeld het digitaal gezagsregister zien dat (digitale) techniek in het familierecht ook nu al een nuttige functie vervult. Op die wijze zouden ouders kunnen zien wat de juridische situatie is ten opzichte van het kind. Als de status verandert, zouden de ouders een melding kunnen krijgen. De betrouwbaarheid van de BRP is zeer groot (boven de 95\%), maar niet waterdicht. Dat betekent dat denkbaar is dat een man vader wordt, voor wie dat niet de bedoeling is. Daarom moet worden nagedacht over de mogelijkheid om administratiefouten eenvoudig te herstellen. Voor het overige zouden de regels voor de ontkenning van het ouderschap gelden (art. 1:200 BW), zoals die nu ook voor gehuwde ouders en geregistreerde partners van toepassing zijn.

\section{Conclusie}

Het recht, dat ook wel de spiegel van de maatschappij genoemd wordt, reflecteert soms nog het spiegelbeeld uit het verleden. De maatschap- 
pelijke veranderingen ten aanzien van relaties zijn hard gegaan; het recht heeft die veranderingen aardig weten bij te houden. Voor zover kan worden vastgesteld op basis van de schaarse empirische aanwijzingen werkt zowel het afstammings- als het gezagsrecht voor het overgrote deel van de ongehuwd samenwonende ouders naar behoren. Is aanpassing, zoals D66 bijvoorbeeld betoogt, dan overbodig? Dat blijkt niet het geval te zijn. Door het van rechtswege verbinden van afstamming en gezag voor de vader aan het ongehuwd samenwonen met de moeder wordt de positie van kind en vader beter beschermd. Het is in het belang van alle betrokkenen - ook van de moeder - dat een dergelijke regeling conflicten over deze onderwerpen voorkomt, omdat op voorhand al helder is hoe het juridisch geregeld is en de positie van het kind en de vader minder afhankelijk van de moeder is. Daarnaast maakt dit het voor de almaar groeiende groep ongehuwd samenwonende ouders makkelijker om met alleen de geboorteaangifte beide aspecten goed te regelen. Door aanknoping aan geboorteaangifte en registratie op hetzelfde woonadres in de BRP worden de ongehuwd samenwonende ouders goed afgebakend. Op die manier zou het recht de maatschappij nog beter weerspiegelen. Het woord is aan de Staatscommissie Herijking Ouderschap.

\section{Literatuur}

\section{Asser/De Boer 2010}

J. de Boer, Mr. C. Assers Handleiding tot de beoefening van het Nederlands burgerlijk recht.

1. Personen-en familierecht, Deventer: Kluwer 2010.

\section{CBS 2016}

CBS, 'Ouders van ruim vier op de tien baby's niet getrouwd', nieuwsbericht 2016/21, 23 mei 2016.

\section{Van Opijnen 2014}

M. van Opijnen, Op en in het web. Hoe de toegankelijkheid van rechterlijke uitspraken kan worden verbeterd (diss. Amsterdam UvA), Den Haag: Boom Juridische uitgevers 2014.

\section{Schrama 2015}

W.M. Schrama, 'Vervangende toestemming voor erkenning: een analyse van recente rechtspraak', Tijdschrift voor Familieen Jeugdrecht 2015, afl. 9, p. 176-181. 


\section{Schrama 2016a}

W.M. Schrama, 'Over vaders, seks en afstamming: het afstammingsrecht voor verwekkers kritisch beschouwd', Ars Aequi 2016, p. 212-218.

\section{Schrama 2016b}

W.M. Schrama, 'Van rechtswege vader met gezamenlijk gezag', Tijdschrift voor Familie- en Jeugdrecht 2016, afl. 5, p. 103.

\section{SCP/CBS 2014a}

SCP/CBS, Emancipatiemonitor 2014, Den Haag: SCP/CBS 2014.

SCP/CBS 2014b

SCP/CBS, Armoedesignalement 2014, Den Haag: SCP/CBS 2014.

\section{Vlaardingerboek 2014}

P. Vlaardingerboek (red.), Het

hedendaagse personen- en familierecht, Deventer: Kluwer 2014.

Vonk 2007

M. Vonk, Children and their parents, Antwerpen: Intersentia 2007.

\section{Wortmann 2016}

S.F.M. Wortmann, 'Art. 1:253c BW', in: S.F.M. Wortmann (red.), Groene Serie Personen- en familierecht, Deventer: Kluwer (losbladig en online, laatst bijgewerkt op 1 mei 2016). 